\title{
Pheochromocytoma - An Unusual Presentation - A Case Report
}

\author{
I PRASAD ${ }^{\mathrm{a}}$, ZA LATIF ${ }^{\mathrm{b}}$, F PATHAN ${ }^{\mathrm{N}}$, SM ASHRAFUZZAMAN ${ }^{\mathrm{d}}$, F AMIN ${ }^{\mathrm{e}}$
}

\begin{abstract}
Summary:
This case report is of a 50yrs old man who got admitted in BIRDEM Hospital in a state of unconsciousness for 5 hours .He is a known case of hypertension and diabetes mellitus for the last 12 years and was on insulin. Hypoglycemia was detected, treated with intravenous glucose and the patient regained consciousness. On further query he complained of repeated episodes of nausea, palpitation and sweating for the last 12 years. The episodes were initially labeled as hypoglycemia but blood sugar was never found in hypoglycemic range. The patient was on multiple antihypertensive medications but blood pressure was uncontrolled. All the investigations were normal including 24hrs urinary VMA, serum adrenalin and noradrenalin except ultrasonography of whole abdomen which showed a
\end{abstract}

\section{Introduction}

Pheochromocytomas are adrenomedullary catecholamine secreting tumors and extra adrenal catecholamine secreting tumors are called paragangliomas. ${ }^{1}$ The frequency of diagnosis is 2 patients per million people yearly in the western world, accounting for $<1 \%$ cause of hypertension. ${ }^{2}$ There is no epidemiological data of pheochromocytoma in Bangladesh. Sustained or episodic hypertension in these cases is often resistant to conventional therapy. ${ }^{1}$ Triad

a. Dr. Indrajit Prasad FCPS (Medicine), MD (Endocrinology and Metabolism), OSD (DGHS), deputed to Department of Endocrinology, BIRDEM.

b. Professor Zafar Ahmed Latif FCPS (Medicine), Professor and Head, Department of Endocrinology, BIRDEM.

c. Dr. Faruque Pathan MD (Endocrinology and Metabolism), Associate Professor, Department of Endocrinology, BIRDEM.

d. Dr. S.M. Ashrafuzzaman MD (Endocrinology and Metabolism), Assistant Professor, Department of Endocrinology, BIRDEM.

e. Dr.Firoz Amin MD (Endocrinology and Metabolism), Registrar, Department of Endocrinology, BIRDEM

Address of Correspondenc: Dr. Indrajit Prasad, 14/c kalibari road, Mymensingh, Tel-01552321322, Email- drindrajit1976@yahoo.com Received: 10 April, 2008

Accepted: 7 May, 2009 mass measuring $72 x 76 \mathrm{~mm}$ in left suprarenal region. One night the patient again developed palpitation, chest discomfort, severe headache and profuse sweating. Blood pressure was recorded $240 / 160 \mathrm{mmHg}$. Blood sample was drawn for adrenalin, noradrenalin, 24hrs urine collection was done for VMA and was found very high. The patient was diagnosed as having left adrenal pheochromocytoma. After controlling blood pressure and other preoperative preparations left adrenalectomy was done. Histopathology revealed phaeochromocytoma. Per and postoperative periods were quite eventful. Blood pressure was normal without any antihypertensive drug during discharge. The patient was discharged with the advice to come for follow up after 1 month.

(J Bangladesh Coll Phys Surg 2010; 28: 113-116)

of symptoms in pheochromocytoma includes palpitation, headache and sweating. ${ }^{3}$ Complications are left ventricular failure, dysrhythmias, pulmonary oedema, carbohydrate intolerance, cerebrovascular accident and hypertensive enncephalopathy. ${ }^{1}$ Pheochromocytoma is called $10 \%$ tumor because $10 \%$ are malignant $10 \%$ are bilateral $10 \%$ are familial and recurrence rate is $10 \% .^{1}$ Screening should be done in the following situations a) young patients with hypertension, b) patients with paroxysmal symptoms, 3) patients with family history of MEN, VHL, neurofibromatosis, 4) patients developing hypertensive crisis during general anesthesia or surgery 5) patients with unexplained heart failure. ${ }^{1}$ We must have a high degree of suspicion for diagnosis of pheochromocytoma. Blood and urine samples should be taken during or immediately after the paroxysm. ${ }^{3}$ Twenty-four hours urinary free catecholamines are more sensitive than urinary metanephrins and VMA. ${ }^{1}$ Imaging should be done to localize the tumor. Dynamic tests are not popular. ${ }^{1}$ Surgery is the treatment of choice.$^{3}$ Meticulous pre, per and postoperative measures are essential for better outcome. ${ }^{3}$ Mortality from elective 
surgery is $2 \% .{ }^{2}$ Lifelong follow-up is needed in these cases. $^{2}$

\section{Case report}

Mr. M A a 50years old businessman hailing from laxmipur sadar got admitted in BIRDEM on December 18, 2006 with the history of unconsciousness for 5 hours. According to the statement of his wife he is a known case of diabetes mellitus and hypertension for the last12 years. He was on insulin, missed the breakfast on the day of incidence and became unconscious. He was brought to BIRDEM; hypoglycemia was detected,

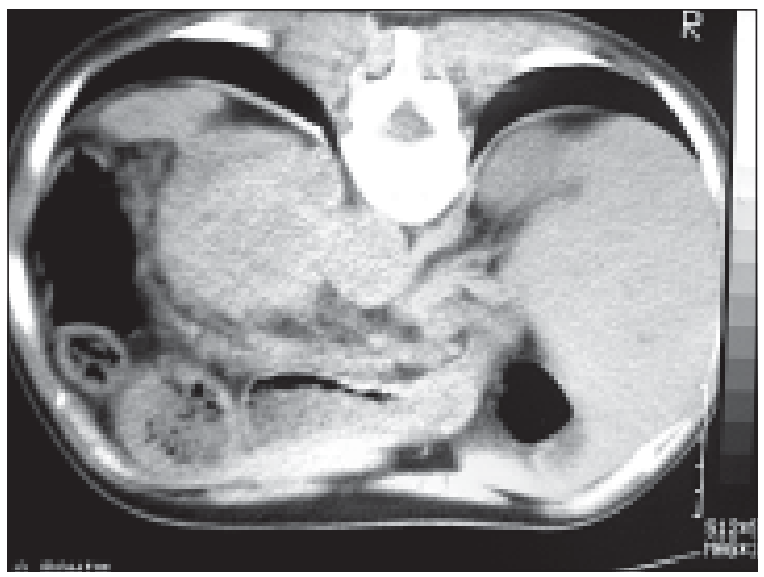

Fig.-1: CT scan of abdomen shows left adrenal mass.

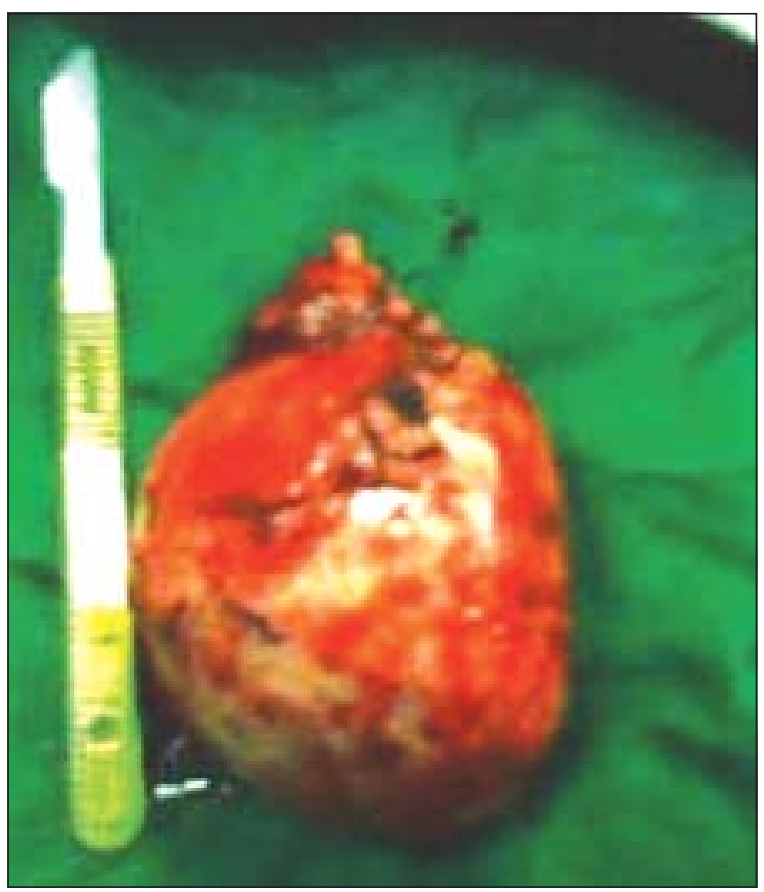

Fig.-2: Resected left adrenal mass. treated with intravenous glucose and the patient regained consciousness. On further query he also complained of repeated episodes of nausea, palpitation, sweating and

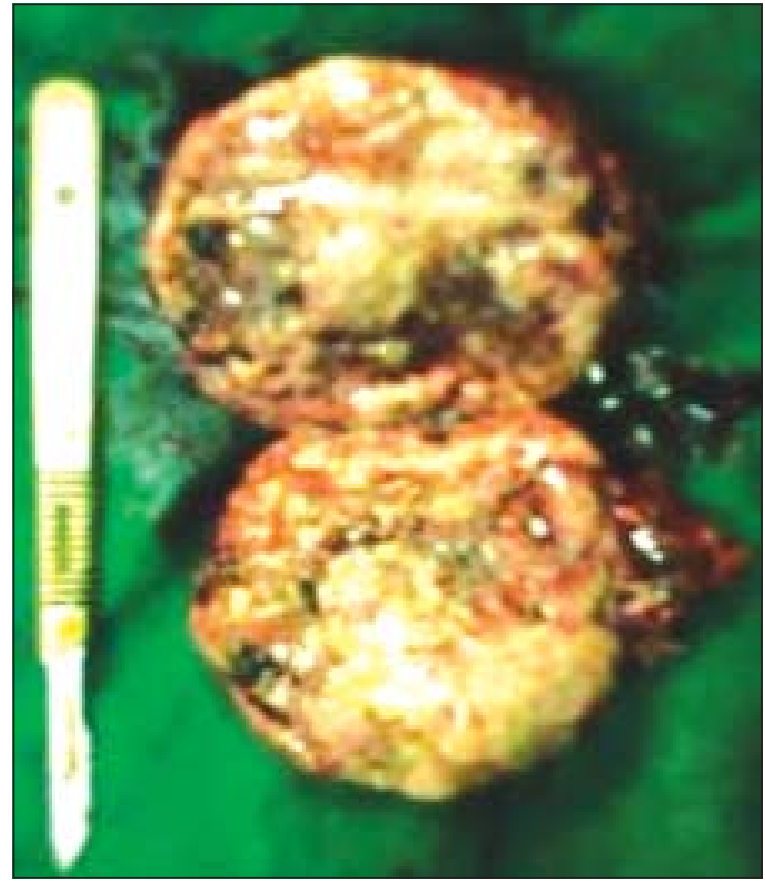

Fig.-3: Bisected left adrenal mass.

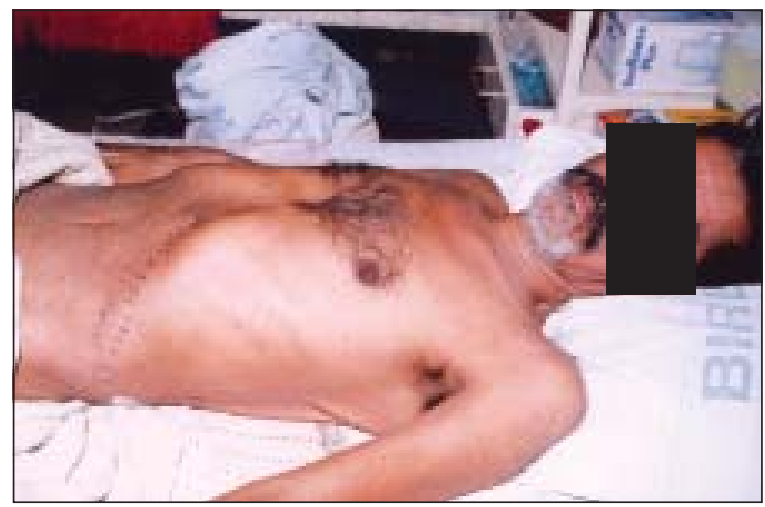

Fig.-4: Mr. MA after left adrenalectomy.

chest discomfort for the last 12 years. But the episodes were not associated with unconsciousness. Each episode lasted for about half an hour; there was no precipitating factor and the symptoms were relieved spontaneously. The episodes were initially labeled as hypoglycemia but blood sugar was never found in hypoglycemic range. The patient's father was diabetic and none of his other first-degree relatives suffered from any other known endocrine disorder. The patient was on premixed insulin 
and tablet amlodipin, atenolol and lisinopril. The patient appeared anxious; pulse was 110 beats / min. blood pressure 180/100 mmHg. Other physical findings were normal. Our provisional diagnosis was diabetes mellitus, hypoglycemia, and hypertension secondary to pheochromocytoma. The deferential diagnoses for hypertension and the paroxysms were essential hypertension, panic attacks, repeated hypoglycemia, and thyrotoxicosis. Investigation on18/12/2006 revealed no abnormality except HbA1c 7.3\%. ECG showed sinus tachycardia, thyroid functions and serum electrolytes

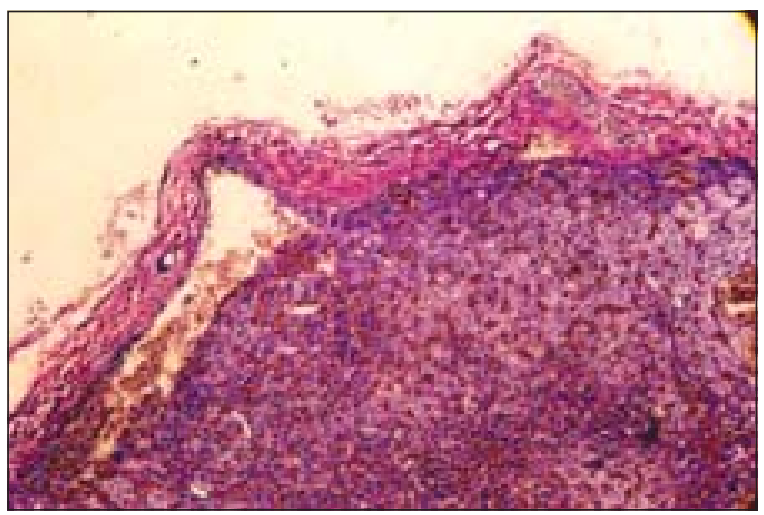

Fig.-5: Low power microscopic view shows pheochromocytoma.

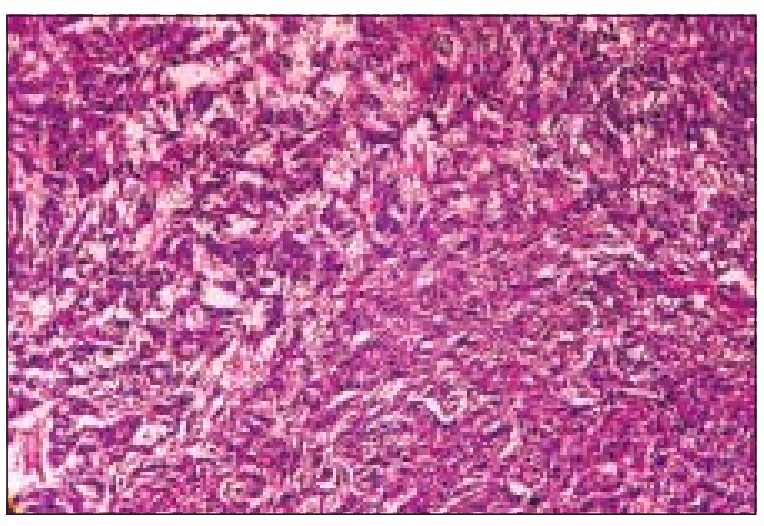

Fig.-6: High power microscopic view shows pheochromocytoma.

were normal. On 22/12/06 24Hrs urinary VMA was12.89 mg/day (normal up to $15 \mathrm{mg} /$ day), serum adrenalin was $93 \mathrm{pg} / \mathrm{ml}$ (normal up to $125 \mathrm{pg} / \mathrm{ml}$, serum noradrenalin was $285 \mathrm{pg} / \mathrm{ml}$ (normal up to $600 \mathrm{pg} / \mathrm{ml}$ ), basal, 5 pm cotisol and low dose dexamethasone suppression test were normal. Ultrasonogram of the whole abdomen on 24/12/06 showed a rounded mixed echogenic area measuring about $72 \times 76 \mathrm{~mm}$ in left suprarenal region. On 02/01/06 at 1.00 am the patient again developed palpitation, chest discomfort, profuse sweating, severe headache and restlessness. His blood pressure at that time was $240 / 160 \mathrm{mmHg}$ and he was managed with intravenous GTN. Blood was drawn for sugar, serum adrenalin, noradrenalin and 24Hrs urine collection started for VMA measurement. Blood sugar level was $7.8 \mathrm{mmol} / \mathrm{l}$ but this time $24 \mathrm{Hrs}$ urinary VMA was $46.4 \mathrm{mg} /$ day(normal up to $15 \mathrm{mg} /$ day), serum adrenalin was $620 \mathrm{pg} / \mathrm{ml}$ (normal up to $125 \mathrm{pg} / \mathrm{ml}$, serum noradrenalin was $3260 \mathrm{pg} / \mathrm{ml}$ (normal up to 600pg/ $\mathrm{ml})$.CT scan of abdomen showed a rounded mixed density mass measuring $78 \times 75 \mathrm{~mm}$ in left suprarenal region. Final diagnosis of left adrenal phochromocytoma was reached. After controlling blood pressure with prazosin and carvedilol, surgical consultation was taken and finally on 14/1/06 left sided adrenalectomy was done. During induction of anesthesia and manipulation of the tumor blood pressure was raised upto $240 / 140 \mathrm{~mm}$ Hg which reduced to $60 / 30 \mathrm{mmHg}$ after clamping the adrenal vessels. In the peroperative period hypertension was controlled with intravenous esmolol and GTN; hypotension was managed with intravenous dopamine and adrenaline. On the $1^{\text {st }}$ postoperative day the patient suddenly lost his consciousness and was transferred to ICU. At that time blood sugar was normal , blood pressure was unrecordable. ECG was normal and there was no focal neurological deficit. The patient was put on ventilator.CT scan of head and serum cortisol was normal. Intravenous dopamine was started. The patient recovered after 4 days. Histopathology revealed left adrenal pheochromocytoma. After 7 days he was discharged with normal blood pressure without any antihypertensive drug. He was advised to come for follow up after 1 month.

\section{Discussion:}

Pheochromocytomas are rare tumors and rare cause of hypertension. ${ }^{3}$ The frequency of diagnosis is 2 patients per million people yearly in the western world. ${ }^{2}$ But the reported incidence in a mayo clinic autopsy series varied from about 250 to 1300 cases per million. Considering this autopsy data it is clear that the great majority of pheochromocytoma cases are not diagnosed during life. This is due to protean manifestation of the disease. ${ }^{2}$ In this case the patient was experiencing repeated bouts of 
typical symptoms of pheochromocytoma for the last12 years but the diagnosis was delayed. Clearly we must become more vigilant for pheochromocytoma and employ appropriate screening tests for all patients in whom pheochromocytoma enters into in deferential diagnosis. Common factors precipitating a crisis are straining, exercise, pressure on abdomen, surgery, anesthesia and unopposed b blockade. ${ }^{1}$ In our case there was no precipitating factor except the preoperative procedures. Catecholamines have short half-lives and are secreted episodically .A random plasma measurement may miss peak catecholamine levels. On the other hand plasma levels are particularly helpful when samples are collected during a paroxysm. ${ }^{3} \mathrm{We}$ prepared the patient with sequential a and b blockade, volume expansion with intravenous normal saline and high sodium diet but we could not prevent the post operative shock. It seems that we should have adopted other recommended measures like preoperative autologous blood transfusion, ICU transfer one day before surgery with intravenous, arterial and swan Gang catheters. ${ }^{4}$ Followup is life long. Blood pressure should be measured weakly in the $1^{\text {st }}$ year and monthly thereafter. ${ }^{2}$ Querterly 24Hrs urine collection for catecholamines during $1^{\text {st }}$ year then annually or semiannually for at least 5 yrs. Five years survival rate for pheochromocytoma in benign cases is $97 \%$ and in malignant cases is $23-44 \% .^{5-7}$

\section{References:}

1. Helen E. Turner, John AH Wass. Pheochromocytomas and paragangliomas. Oxford Hand book of Endocrinology and Diabetes. Oxford university press, 2002.pp329-342

2. Paul a. Fitzgerald, Alan Goldfien. Adrenal medulla. Basic and Clinical Endocrinology, 7th edition. McGraw-Hill, 2004.pp439-477.

3. Robert G. Dluhy, Jennifer E. Lawrence, Gordon H. Williams. Endocrine hypertension. Williams Textbook of Endocrinology, 10th edition. Saunders, 2003. pp 52-85.

4 Russell WJ, Metcalfe IR, Tonkin AL. The preoperative management pheochromocytoma. Anaesth Intensive Care1998; 26:196-200.

5 Sheps SG, Jiang NS, Klee GG. Recent development in the diagnosis and treatment of pheochromocytoma. Mayo Clinic Proc 1990; 65:88-95.

6 Gifford RW, Manger WM, Bravo EL. Pheochromocytoma. Endocrinol Metab Clinic North Am1994; 23:387-404.

7 Plouin PF, Chatellier G, Fofol I.Tumor recurrence and hypertension persistence after successful pheochromocytoma operation. Hypertension1997; 20:1133-39. 